\title{
Standardization of Korean Speech Audiometry
}

\author{
Junghak Lee \\ Institute of Audiology, Department of Audiology, Hallym University of Graduate Studies, Seoul, Korea
}

한국 어음청각검사의 표준화

이 정 학

한림국제대학원대학교 청각학과 . 청각언어연구소

\begin{abstract}
This study aims to review papers and standards for Kerean speech audiometry (KSA) and provide clinically useful information. Korean and international standards as well as research papers related to the KSA were reviewed in terms of the assessment of hearing function in connection with diagnostic evaluation and audiological rehabilitation. The Korean standard (KS I ISO 8253-3) for speech audiometry was developed based on the international standard of ISO 8253-3, which includes procedures to measure speech recognition threshold (SRT), word recognition score (WRS) and sentence recognition score (SRS). Each procedure has separate speech lists for three age groups; 3-5 years old, 6-12 years old and 13 years and older. Recently several studies have reported the test-retest reliability of each speech list for each procedure for each age group to use conveniently in various clinical areas. More specifically they presented tables of $95 \%$ confidence intervals and prediction intervals for each WRS and SRS from 0 to $100 \%$ for each age group. The above results would provide reasonable evidence for determining whether retest scores for some groups or individuals would be significantly different from test scores. In order to demonstrate clinically meaningful differences in speech audiometry, test scores close to the center (50\%) tend to have retest scores with bigger differences than those close to 0 or $100 \%$.
\end{abstract}

Key Words: Speech audiometry, Korean standard, Test-retest reliability, Confidence interval, Prediction interval.

Received: February 10, 2016 / Accepted: March 10, 2016

Correspondence: Junghak Lee, Institute of Audiology, Department of Audiology, Hallym University of Graduate Studies, 427 Yeoksam-ro, Gangnam-gu, Seoul 06197, Korea

Tel: +82-2-2051-4950 / Fax: +82-2-3453-6618 / E-mail: leejh@hallym.ac.kr

\section{INTRODUCTION}

어음을 이용한 청력검사기가 1920년 대 중반 처음으로 개발 된 이래 다양한 검사방법과 검사장비가 지속적으로 발전되어 오고 있다(McArdle \& Hnath-Chisolm, 2009). 특히 제 2차 세 계대전 이후, 미국에서 전시에 청력이 손상된 군인들의 치료와 재활을 위하여 좀 더 체계화된 어음을 이용한 보청기 평가 방 법들이 개발되었으며, 어음인지능력과 검사강도와의 상관관계 등을 연구하면서 더 많은 발전을 해왔다. 어음청각검사(speech audiometry)는 단음절, 이음절, 문장 등을 이용하여 청력역치 및 어음인지도를 측정하는 검사를 의미한다(Lee et al., 2014). 이러한 검사 결과는 보청기, 인공와우(cochlear implant) 등 청 각보조장치의 착용효과, 청능재활의 평가 및 중추청각장애 (central auditory processing disorder, CAPD)를 평가하는데 사용되기도 한다(Lee et al., 2010).
일반인 뿐만 아니라 학령기 및 학령전기 아동들에게도 어음 을 이용한 청각검사방법은 비언어음을 이용한 청각검사보다 의 사소통능력을 측정하기에 타당하며, 특히 아동의 청력역치검 사에서 순음으로 측정하는 것보다 더 높은 성공률을 이끌어 낼 수도 있다. 또한 최근 보청기 및 인공와우 시술을 받는 아동 이 증가하면서 보청기 적합 또는 수술 후의 재활에 대한 관심 이 증폭되고 있다. 이처럼 보장구를 착용한 후 재활과정에 있 는 아동들의 경우, 순음청각검사만으로는 종합적인 청각능력 을 판단하는데 어려움이 있어 반드시 어음청각검사를 통해서 보완해야 한다. 그러므로 청각장애인을 대상으로 하는 어음청 각검사는 정확한 청력손실의 측정과 의사소통에 미치는 영향 을 조기에 발견하여 적절한 증폭 및 청능재활을 가능케 할 것 이다.

어음을 사용하는 청각검사는 어느 정도 신뢰성과 동질성이 있는 객관적인 평가결과를 얻기 위하여 검사어표 뿐만 아니라 
검사절차의 표준화도 요망된다. 이러한 표준화를 위해서는 공 업규격에 맞는 어음청력기기, 성능이 우수한 전기음향기기, 잡 음을 차단하는 방음실, 녹음 방식 등이 필요 요건이다. 대부분 의 선진국에서는 국제표준협회(International Organization for Standardization, ISO)에서 권장하는 어음청각검사 방법(ISO 8253-3, 1996)을 국가표준에 적용해서 자국의 어음청각검사방 법을 개발하여 사용하고 있다. 우리나라에서도 국제표준에서 권장하는 절차에 따른 어음청각검사방법의 개발이 이루어졌으 며(KS I ISO 8253-3, 2009; Lee et al., 2010), 일부 내용은 개 정된 국제표준에 등록되어 있다(ISO 8253-3, 2012).

\section{한국어음청각검사 도구의 개발}

한국어음청각검사(Korean Speech Audiometry, KSA) 방법 에 대한 국가표준(KS I ISO 8253-3, 2009)은 기존의 연구결과 (Hahm, 1986; Byun et al., 2007)와 국제표준(ISO 8253-3, 1996)의 권장사항을 바탕으로 개발되었다. 이 표준에 제시되어 있는 한국어음은 어음인지역치(speech recognition threshold, $\mathrm{SRT}$ ) 검사를 위한 이음절 어표(bisyllabic word list, BWL), 단 어인지도(word recognition score, WRS) 검사를 위한 단음절 어표(monosyllabic word list, MWL), 문장인지도(sentence recognition score, SRS) 검사를 위한 문장표(sentence list, $\mathrm{SL})$ 로 구성되어 있다. 이음절 어표, 단음절 어표 및 문장표의 어음은 지식경제부(현 산업통상자원부)가 실시한 국가표준화 기술개발사업의 연구결과에 의해 주파수, 강도 및 어표간 난이 도를 고려하여 제작한 $\mathrm{CD}$ 음원을 첨부하였다. 피검자는 연령 에 따라서 일반(adult, A), 학령기 아동(schooler, S) 및 학령전 기아동(preschooler, P)으로 구분한다.

국가표준 이음절 어표(KS-BWL), 단음절 어표(KS-MWL) 및 문장표(KS-SL)는 각 연령대에 적합하도록 일반용(만 13세 이상), 학령기용(만 6 12세) 및 학령전기용(만 3 5세)으로 각 각 나누어 제작하였다(Cho et al., 2008a; Cho et al., 2008b; Han et al., 2011; Jang et al., 2008a; Jang et al., 2008b; Kim et al., 2008a; Kim et al., 2008b; Lee et al., 2010). 이러한 어표 를 사용하는 어음청각검사의 기본적인 절차는 국가표준(KS I ISO 8253-3, 2009)의 부록에 수록되어 있으며 해석방법을 포 함한 보다 자세한 사항은 전문가지침서(Lee et al., 2010)에 수 록되어 있다.

\section{어음청각검사 도구의 임상적용}

임상적으로 어음청각검사 결과는 이과적 치료, 보청기적합, 청능재활 전후의 어음인지능력을 비교 평가하는데 유용하다.
하지만 어느 정도의 점수 변화가 임상적으로 의미가 있는지에 대한 기준을 구축하기 위해서는 검사-재검사 신뢰도 검증이 추가로 필요하다. 최근 여러 연구들이 개발된 한국어음청각검 사의 각 연령대에 따른 단음절 어표, 이음절 어표 및 문장표에 대한 검사-재검사 신뢰도 검정을 국제표준(ISO 8253-3, 2012) 에서 권장하는 방법에 따라서 시행하고 그 결과를 보고하였다 (Jin \& Lee, 2015; Kim et al., 2015; Lee et al., 2015; Lee \& Lee, 2014; Yoon \& Lee, 2015).

이 연구들의 특징은 재검사 신뢰도를 확립하기 위해서 상관 분석과 95\% 신뢰구간(confidence interval, CI) 외에 95\% 예측 구간(prediction interval, PI)을 제시하였다. 예측구간은 개개 인의 신뢰구간을 의미하는 용어로써 집단의 신뢰구간과 구분 하기 위하여 사용하고 있다. 세부적으로는 먼저 전구간에 대한 검사-재검사 점수의 상관분석, 평균과 표준편차(standard deviation, $\mathrm{SD}$ )의 분석 및 신뢰구간을 구하였고, 둘째, 국제표준 (ISO 8253-3, 2012)에서 권장하는 방법을 사용하여 문장인지 도를 50\%, 60\%, 70\%, 80\% 및 90\% 점수구간으로 구분하여 구 간별 예측구간을 확인하고자 하였다. 마지막으로 점수대별 예 측구간에 근거하여 임상에서 사용하기 편리하도록 각각의 단 어인지도 또는 문장인지도에 대한 점수 별(0점 100점) 95\% 예 측구간을 제시하여 개인의 재검사시 보다 정확한 해석을 할 수 있는 근거를 마련하였다.

이러한 예측구간의 특징은 단어인지도와 문장인지도 모두 재검사에서 의미 있는 차이를 보이기 위해서는 기본검사점수, 즉 치료 또는 훈련 전에 측정한 점수가 중간지점(50점) 부근일 때가 양측 끝 지점(0점, 100점)에 가까울 때보다 더 많은 점수 차이가 필요하다는 점이다. 전반적으로 문장인지도의 예측구 간이 단어인지도 예측구간보다 더 넓어서 재검사신뢰도 측면에 서 단음절 어표를 사용할 때 더 높다고 할 수 있다.

\section{CONCLUSION}

어음청각검사는 순음청각검사와 더불어 청력측정에 필수적 인 검사도구이다. 최근 개발한 한국어음청각검사 방법은 국제 표준에서 권장한 방법으로 개발하였기 때문에 검사절차를 준 수하여 측정한 결과는 신뢰할 수 있을 것이다. 특히 일반용 단 음절표와 문장표를 사용한 어음청각검사의 재검사에서 개개인 의 예측구간은 전국적 분포의 충분한 피검자를 대상으로 한 자료에 근거하였기 때문에 임상에서 사용하기에 적절하다고 판 단한다. 하지만 학령기와 학령전기 아동은 대상수가 적고 지역 적으로 편포되어 있어서 임상 적용시 주의가 필요하며 추가 자 료를 보완한 다음 예측구간을 확인할 필요가 있다. 향후 소음 하 어음청각검사의 예측구간도 구축하면 임상에서 더욱 다양 
하게 활용할 수 있을 것이다.

중심 단어 : 어음청각검사-한국표준·검사-재검사 신뢰도·신 뢰구간 · 예측구간.

\section{Acknowledgments}

This research was sponsored by a grant from the Korean Ministry of Trade, Industry \& Energy, Project No. 10041529.

\section{REFERENCES}

Byun, S. W., Oh, S. H., Chae, S. W., Park, S. N., Shim, Y. J., \& Cho, K. K. (2007). Compromises between the frequencies of the colloquial phonemes and those of a new monosyllabic words list in Korean. Korean Journal of Otorhinolaryngology-Head and Neck Surgery, 50(7), 573578.

Cho, S. J., Lee, J. H., Lim, D. H., Lee, K. Y., \& Han, H. K. (2008). Development of school aged and preschool Korean bisyllabic word lists for speech recognition threshold test. Audiology, 4(1), 37-47.

Cho, S. J., Lim, D. H., Lee, K. Y., Han, H. K., \& Lee, J. H. (2008). Development of Korean standard bisyllabic word list for adults (KS-BWL-A) used in speech recognition threshold test. Audiology, 4(1), 28-36.

Hahm, T. Y. (1986). Complementary study on construction of Korean word wists for speech audiometry. Inje Medical Journal, 7(1), 1-19.

Han, H. K., Lee, J. H., Cho, S. J., Kim, J. S., Lee, K. W., \& Choi, W. D. (2011). Reference sound pressure level for Korean speech audiometry. International Journal of Audiology, 50(1), 59-62.

ISO 8253-3 (1996). Acoustics-Audiometric test methods-Part 3: Speech audiometry. Geneva: International Organization for Standardization.

ISO 8253-3 (2012). Acoustics-Audiometric test methods-Part 3: Speech audiometry. Geneva: International Organization for Standardization.

Jang, H. S., Lee, J. H., Lim, D. H., Jeon, A. R., \& Hyun, J. H. (2008). Development of Korean standard sentence lists for preschoolers used in sentence recognition test. Audiology, 4(2), 178-187.
Jang, H. S., Lee, J. H., Lim, D. H., Lee, K. W., Jeon, A. R., \& Jung, E. J. (2008). Development of Korean standard sentence lists for sentence recognition test. Audiology, 4(2), 161-177.

Jin, S. O. \& Lee, J. H. (2015). Test-retest reliability of speech recognition thresholds using the Korean standard bisyllabic word list for adults (KS-BWL-A). Audiology, 11(2), 156-162.

Kim, J. S., Lim, D. H., Hong, H. N., Shin, H. W., Lee, K. D., Hong, B. N., et al. (2008). Development of Korean standard monosyllabic word lists for adults (KS-MWL-A). Audiology, 4(2), 126-140.

Kim, J. S., Lim, D. H., Hong, H. N., Shin, H. W., Lee, K. D., Hong, B. N., et al. (2008). Development of Korean standard monosyllabic word lists for school aged children (KS-MWL-S) and preschoolers (KS-MWL-P). Audiology, 4(2), 141-160.

Kim, J.S., Lee, J.H., \& Park, J.H. (2015). Test-retest reliability of word recognition score (WRS) using Korean standard monosyllabic word lists for adults (MWL-A) as a function of the number of test words. Journal of Audiology and Otolaryngology, 19(2), 68-73.

KS I ISO 8253-3 (2009). Acoustics-Audiometric test methods-Part 3: Speech audiometry. Eumseong-gun: Korean Agency for Technology and Standards.

Lee, J. H., Cho, S. J., Kim, J. S., Jang, H. S., Lim, D. H., Lee, K, W., et al. (2010). Korean speech audiometry (KSA). Seoul: Hakjisa.

Lee, J. H., Lee, K. Y., Lee, J. H., \& Bahng, J. (2014). Glossary of audiuology. Seoul: Hakjisa.

Lee, H. W. \& Lee, K. W. (2014). The test-retest reliability of the word lists of Korean speech audiometry for preschoolers. Audiology, 10(2), 25-34.

Lee, J. H., Lee, K. W., Lee, J. H., Bahng, J., Kim, J. S., Choi, C. H., et al. (2015). Test-retest reliability of sentence recognition score using Korean standard sentence lists for adults (KS-SL-A). Audiology, 11(1), 17-25.

McArdle, R. \& Hnath-Chisolm, T. (2009). Speech Audiometry. In J. Katz, L. Medwetsky, R. Burkard, \& L. Hood (6 ${ }^{\text {th }}$ Ed.), Handbook of clinical audiology (pp. 64-79). Baltimore, MA: Lippincott Williams \& Wilkins.

Yoon, J. Y. \& Lee, J. H. (2015). The test-retest reliability of Korean standard language lists for schoolchildren in speech audiometry. Audiology, 11(1), 26-36. 